\title{
Reaching Those Most in Need - A Call to Action for Advanced \\ Parkinson's Disease
}

\author{
Shashank Agarwal and Jori E Fleisher
}

Marlene and Paolo Fresco Institute for Parkinson's and Movement Disorders, Department of Neurology, New York University School of Medicine, New York, US

DOI: http://doi.org/10.17925/ENR.2016.11.01.20

\begin{abstract}
Much of the clinical and research attention for Parkinson's disease (PD) has focused on mild to moderate stages. As the disease advances, it can become difficult for patients to attend clinical visits. These patients are often lost to follow-up, and consequently, vanish from the pool of potential research subjects who could inform our management of this understudied population. We aim to increase awareness about this population and potential interventions to improve continuity of care and foster research in advanced PD.

\section{Keywords}

Parkinson's disease, health services research, models of care, unmet needs

Disclosure: Shashank Agarwal has nothing to disclose in relation to this article. Jori E Fleisher has received research support from the Parkinson Council, the Parkinson Alliance, and the National Institutes of Health. This article is a short opinion piece and has not been submitted to external peer reviewers. No funding was received in the publication of this article.

Open Access: This article is published under the Creative Commons Attribution Noncommercial License, which permits any non-commercial use, distribution, adaptation and reproduction provided the original author(s) and source are given appropriate credit.

Received: 8 April 2016 Published Online: 20 April 2016 Citation: European Neurological Review, 2016;11(1): 20-1

Correspondence: Jori Fleisher, 240 E. 38th Street, 20th Floor, NY 10016, US. E: Jori.Fleisher@nyumc.org
\end{abstract}

Parkinson's disease (PD) is a debilitating, progressive and costly neurodegenerative disease that affects over one million people annually in the US. ${ }^{1}$ The four cardinal features of PD are well recognised, namely: tremor at rest, rigidity, bradykinesia and postural instability. Additionally, individuals with PD commonly develop non-motor symptoms such as autonomic dysfunction (orthostatic hypotension, and bowel and bladder dysfunction), neuropsychiatric symptoms (depression, anxiety, cognitive impairment and psychosis), sensory symptoms and sleep disturbances. In fact, patients with PD report an average of nearly 8 non-motor symptoms, with the frequency of such symptoms increasing with disease duration and severity. ${ }^{2}$ Furthermore, as patients age, they are subject to other chronic medical comorbidities, ${ }^{3}$ contributing to significant healthcare costs, ${ }^{4}$ hospitalisations and visits to emergency departments. ${ }^{5}$

As PD advances, non-motor symptoms, motor fluctuations and falls become more prominent and quality of life deteriorates. Advanced PD is commonly defined by clinicians as stage 4 and 5 on the Hoehn and Yahr scale. ${ }^{6}$ As the disease progresses there is an emergence of a symptom constellation that may be non-responsive to levodopa which includes postural instability and falls, speech and swallowing difficulties, and other non-motor symptoms. ${ }^{7}$ As PD advances, so too do polypharmacy, ${ }^{8}$ emergency room visits, and hospitalisation rates. ${ }^{9}$ Older age, increasing functional impairment, dementia, and hallucinations each independently predict institutionalization, with hallucinations being the strongest - and potentially, most treatable - risk factor. ${ }^{10,11}$ Institutionalised PD patients have greater mortality when compared to age- and disease duration-matched community-dwelling patients. ${ }^{12,13}$ Institutionalisation also distances patients from neurological expertise, and causes complex loss and grief for the caregiver. ${ }^{14,15}$ It is for all of these reasons that interventions to delay or prevent institutionalisation are desperately needed.

The role of the main caregiver, usually a family member, is crucial in the care of patients with PD. This responsibility becomes progressively more important with disease progression, with caregivers increasingly shouldering the burden for medication administration, disease management and physical and emotional support. ${ }^{16}$ Published literature in PD points to an association between disease severity and caregiver strain, wherein the presence of visual hallucinations, cognitive impairment and depression in the patient significantly increase their caregiver's strain. ${ }^{17-19}$ Caregiver strain affects not only the caregiver's own quality of life but also their perceived health status; although this relationship has been demonstrated to worsen with increasing PD severity of the patient, individuals with advanced PD are severely underrepresented in such studies. ${ }^{20}$ Currently, the majority of research is focused on mild or moderate PD, and little is known about advanced PD patients. This is due, in large part, to these precise patients' disease severity and functional limitations impairing their access to clinical care. When clinical access is lost, so too is the opportunity to participate in research that would shed light on this stage of disease. Best practices for the treatment of advanced PD are understudied, and just as we have only begun to explore the impact of advanced disease on patients, this remains to be explored in their caregivers, as well. ${ }^{20}$

We need to develop models that provide continuity of care - and as an extension, continuity of research opportunities - to patients with advanced PD. Telemedicine holds great promise for reaching beyond the clinic walls, though logistics may still prove a challenge for the most advanced PD patients. ${ }^{21}$ Outside of neurology, another well-studied 
model is home-based care. Home visit models in various forms have flourished as a means of maintaining or improving the quality of care for complex elderly patients while reducing healthcare costs. ${ }^{22}$ The majority of successful models have been interdisciplinary, incorporating nursing and social work care coordination in primary and specialty care. ${ }^{22-24}$ Although home visits have been published in several other chronic diseases, in the case of PD it is still a relatively unexplored phenomenon. ${ }^{25,26}$ One such interdisciplinary home visit programme for PD and other associated disorders was described in the literature. ${ }^{27}$ This programme lacked the involvement of a neurologist, however, and described neither the patients or volume served, nor the outcomes achieved. A more recent programme is Operation House Call (OHC). This programme demonstrated that it is possible to provide personcentered care in the home setting for PD patients. This innovative programme dispatched a movement disorder fellow to provide and coordinate the care of eight underserved patients with PD, however the authors noted that barriers of replicating such a programme included financial limitations, time constraints, and lack of availability of qualified personnel. ${ }^{28}$ Thus, there is a critical unmet need for rigorously studied, efficacious, and cost-effective programmes that will enable advanced, homebound patients to receive care at home. Such programmes might then allow for these underrepresented patients to participate in research and shed light on the critical, unmet needs of patients with advanced PD and their caregivers.

One such strategy is an Interdisciplinary Home Visit Program for Advanced PD, recently launched at the Marlene and Paolo Fresco Institute for Parkinson's and Movement Disorders at New York University School of Medicine. This novel programme, incorporating neurologic, social work, and nursing disciplines, aims to deliver evidence-based patient- and family-centered care to homebound patients with advanced PD, while prospectively studying patient- and caregiver-centered outcomes. Data are forthcoming, and a thorough investigation into the healthcare system-level cost-effectiveness will be crucial to future implementation and dissemination of such a model at other centers.

Health services research has brought to our attention the urgent need to foster early access to care for PD, both in the US and abroad. ${ }^{29}$ The attendant imperative, then, is to preserve that hard-fought access to care, particularly when patients and caregivers need our expertise, counseling, and compassion the most.
1. Pringsheim T, Jette N, Frolkis A, Steeves TDL, The prevalence of Parkinson's disease: a systematic review and metaanalysis, Mov Disord, 2014;29:1583-90.

2. Barone P, Antonini A, Colosimo C, et al., The PRIAMO study: A multicenter assessment of nonmotor symptoms and the impact on quality of life in Parkinson's disease, Mov Disord, 2009;24:1641-9.

3. Salive ME, Multimorbidity in older adults, Epidemiol Rev, 2013;35:75-83.

4. Alemayehu B, Warner KE, The lifetime distribution of health care costs, Health Serv Res, 2004:39:627-42.

5. Latham LP, Ackroyd-Stolarz S, Emergency department utilization by older adults: a descriptive study, Can Geriatr J 2014:17:118-25.

6. Goetz CG, Poewe W, Rascol O, et al., Movement Disorder Society Task Force report on the Hoehn and Yahr staging scale: status and recommendations, Mov Disord, 2004;19:1020-8

7. Hely MA, Morris JGL, Reid WGJ, Trafficante R, Sydney Multicenter Study of Parkinson's disease: non-L-doparesponsive problems dominate at 15 years, Mov Disord, 2005;20:190-9.

8. Kronish IM, Federman AD, Morrison RS, Boal J, Medication utilization in an urban homebound population, J Gerontol A Biol Sci Med Sci, 2006;61:411-5.

9. Desai NR, Smith KL, Boal J, The positive financial contribution of home-based primary care programs: the case of the of home-based primary care programs: the case of the
Mount Sinai Visiting Doctors, I Am Geriatr SOC, 2008;56:744-9.

10. Keränen P, Martikainen KK, Keränen T, Marttila RJ, Parkinson's disease patients in institutionalized care, Eur Geriatr Med, 2013:4:376-9.
11. Aarsland D, Larsen JP, Tandberg E, Laake K, Predictors of nursing home placement in Parkinson's disease: a population-based, prospective study, J Am Geriatr SoC 2000;48:938-42.

12. Weerkamp NJ, Tissingh G, Poels PJE, et al., Parkinson disease in long term care facilities: a review of the literature, J Am Med Dir Assoc, 2014;15:90-4.

13. Goetz CG, Stebbins GT, Mortality and hallucinations in nursing home patients with advanced Parkinson's disease, Neurology, 1995;45:669-71.

14. Gaugler JE, Mittelman MS, Hepburn K, Newcomer R, Predictors of change in caregiver burden and depressive Predictors of change in caregiver burden and depressive
symptoms following nursing home admission, Psychol Aging 2009:24:385-96.

15. Safarpour D, Thibault DP, Desanto CL, et al., Nursing home and end-of-life care in Parkinson disease, Neurology, 2015;85:413-9

16. McLaughlin D, Hasson F, Kernohan WG, et al., Living and coping with Parkinson's disease: perceptions of informal carers, Palliat Med, 2011;25:177-82.

17. Oguh $\mathrm{O}$, Kwasny M, Carter J, et al., Caregiver strain in Parkinson's disease: national Parkinson Foundation Quality Initiative study, Parkinsonism Relat Disord, 2013;19:975-79.

18. Lökk J, Caregiver strain in Parkinson's disease and the impact of disease duration, Eur J Phys Rehabil Med, 2008:44:39-45.

19. D'Amelio M, Terruso V, Palmeri B, et al., Predictors of caregiver burden in partners of patients with Parkinson's disease, Neurol SCi, 2009;30:171-4.

20. Martinez-Martin P, Arroyo S, Rojo-Abuin JM, et al., Burden, perceived health status, and mood among caregivers of Parkinson's disease patients, Mov Disord, 2008:23:1673-80.
21. Schneider R, Dorsey ER, Biglan $K$, Telemedicine Care for Nursing Home Residents with Parkinsonism, J Am Geriatr Soc 2016;64:218-20

22. Reckrey JM, Soriano $T A$, Hernandez $C R$, et al., The team approach to home-based primary care: restructuring care to meet individual, program, and system needs, J Am Geriatr Soc, 2015;63:358-64

23. Boult $C$, Green AF, Boult $L B$, et al., Successful models of comprehensive care for older adults with chronic conditions: evidence for the Institute of Medicine's "retooling for an aging America" report, J Am Geriatr Soc, 2009;57:2328-37.

24. Reckrey JM, Gettenberg G, Ross $H$, et al., The critical role of social workers in home-based primary care, Soc Work Health Social workers in hom

25. Hall MH, Esposito RA, Pekmezaris R, et al., Cardiac surgery nurse practitioner home visits prevent coronary artery bypass graft readmissions, Ann Thorac Surg, 2014;97:1488-93.

26. Stewart S, Pearson S, Horowitz JD, Effects of a home-based intervention among patients with congestive heart failure discharged from acute hospital care, Arch Intern Med, 1998;158:1067-72

27. Vickers $L F, O^{\prime} N$ Neill $C M$, An interdisciplinary home healthcare program for patients with Parkinson's disease, Rehabil Nurs, 1998;23:286-9.

28. Hack N, Akbar U, Monari EH, et al., Person-Centered Care in the Home Setting for Parkinson's Disease: Operation House Call Quality of Care Pilot Study, Parkinsons Dis, 2015;2015:639494.

29. Dorsey ER, Willis AW, Caring for the majority, Mov Disord, 2013;28:261-2. 